\title{
Strategic Decision Support for Resolving Conflict Existing in Per Aru basin located in Vavuniya district
}

\author{
G. Abira and K.D.W. Nandalal
}

\begin{abstract}
The graph model for conflict resolution (GMCR), along with its associated decision support system GMCR II, is employed for systematically studying the strategic aspects of a conflict existing in Per Aru basin. National Water Supply \& Drainage Board has planned to build a reservoir on the Per Aru for the sole purpose of supplying drinking water to the urban areas of Vavuniya district. People who will be affected due to the inundation of their lands have shown resistance to the construction of the reservoir. Moreover, government organizations such as Forest Department and Wildlife Department also have expressed their concerns over the construction of a reservoir since that will have diverse impacts on forest lands and wildlife in the area that will be inundated by the proposed reservoir. The above three stakeholders, viz., National Water Supply \& Drainage Board, affected people and government organizations suggest a few options to solve the conflict.The options are specific actions that can actually occur in a conflict. The decision support system, GMCR II, was used to investigate and resolve this conflict. The paper presents all the steps involved in the modeling of the conflict using GMCR II and analysis of the results obtained from the model. The National Water Supply \& Drainage Board accepting to reduce the inundation area and agreeing to release sufficient environmental flow was resulted as the best possible solution acceptable for all the three parties.The solution includes affected people and Government Organizations agreeing for the construction of the reservoir at the original location.
\end{abstract}

Keywords: Conflict resolution, decision support system, graph model

\section{Introduction}

Vavuniya is one of the districts in the Northern Province of Sri Lanka situated approximately $280 \mathrm{~km}$ from Colombo. The rainfall of this area is a bimodal dominated by the North-East monsoon (October - March) and South-West monsoon (May-September). The average rainfall of the area is in the range of $800 \mathrm{~mm}$ to $1500 \mathrm{~mm}$.

Major river systems are absent within the Vavuniya district. However, many small to medium scale streams drain through the district and all of them are seasonal streams that are active only during North-East monsoonal rainy periods. KanakarayanAru, ChamaliAru, KiulAru, ChamalankulamAru, Per Aru, KalAru and parts of MalwathuOya are the main river systems draining within the district. These river systems show a remarkable variability in discharge during dry and wet seasons.

The Per Aru shown in Figure 1 originates in the Vavuniya District. TurumpamoddaiAru joins the Per Aru on right side. Afterwards this river is referred to as ParankiAru. Further downstream of the ParankiAru, PeriyakatteAru enters the ParankiAru from the left side. Finally, this river discharges into the Indian Ocean at Mannar. The river basin has an elongated form with a length of about $70 \mathrm{~km}$ and the width ranges from $10 \mathrm{~m}-20 \mathrm{~m}$. The catchment of the ParankiAru is located in the northern dry zone and its area is about $832 \mathrm{~km}^{2}$. Annual discharge volume to sea is about $312 \times 10^{6} \mathrm{~m}^{3}$.

The present water supply scheme to Vavuniya urban area draws water from groundwater and the water supply is limited to $3-4 \mathrm{~h}$ in a day. Besides, after the end of the civil unrest, the area has become popular for living and the population is expected to rise from 36,000 at present to about 93,000 in the year 2030. The

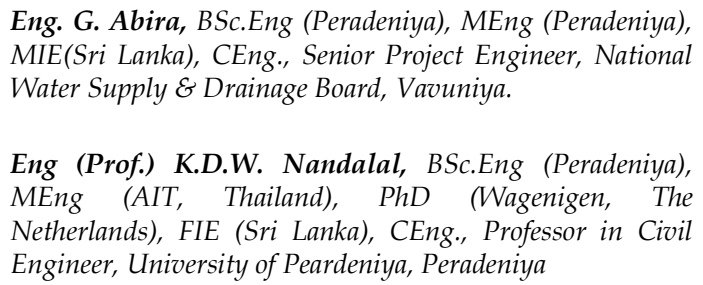

Eng. G. Abira, BSc.Eng (Peradeniya), MEng (Peradeniya), MIE(Sri Lanka), CEng., Senior Project Engineer, National Water Supply E Drainage Board, Vavuniya.

Eng (Prof.) K.D.W. Nandalal, BSc.Eng (Peradeniya), MEng (AIT, Thailand), PhD (Wagenigen, The Netherlands), FIE (Sri Lanka), CEng., Professor in Civil Engineer, University of Peardeniya, Peradeniya 
total water demand will be around $21,000 \mathrm{~m}^{3} /$ day and a maximum of about $3000 \mathrm{~m}^{3}$ / day can be produced by groundwater sources. The rest has to be sought from surface water sources [1].

National Water Supply and Drainage Board (NWSDB) is interested in withdrawing $12,000 \mathrm{~m}^{3} / \mathrm{d}$ of water from the Per Aru by constructing a reservoir across it to cater for the drinking water demand in urban and suburb areas of the Vavuniya district. The plan is to capture the runoff during the Mahaseason, store it, treat it and distribute to the urban areas. During the Maha season there is plenty of water with a significant release of water to the sea and there is no competition on water. But during the dry period and especially during the Yala season there is a conflicting situation between water users. Due to the construction of the proposed storage reservoir on Per Aru some of the paddy, high and forest lands will be inundated. This has created a conflict between the farmers who own lands in the proposed reservoir area and the NWSDB. Additionally, Forest Department and Wildlife Department have shown their concern on the project due to a few issues that may arise as a result of constructing a reservoir on the Per Aru.

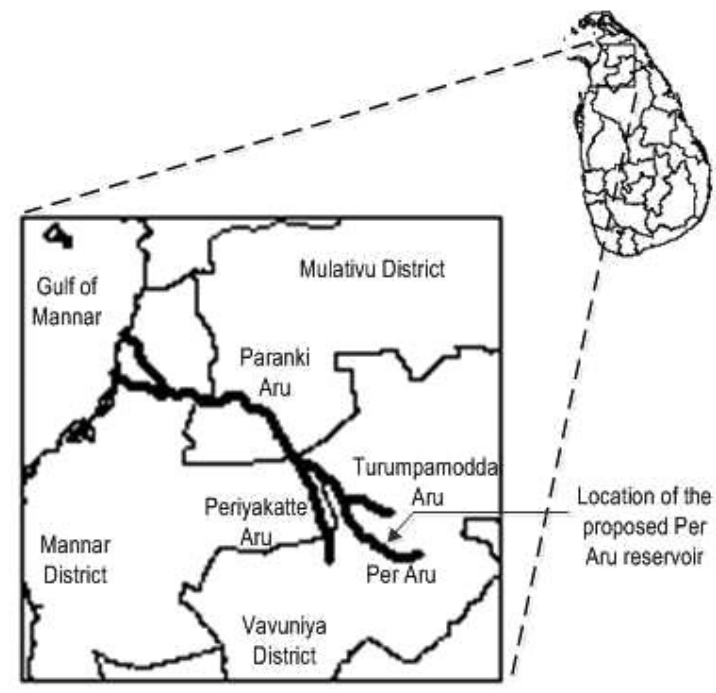

Figure 1 - Per Aru river system

The area that will be inundated by the proposed reservoir belongs to Sastrikoolankulam, Paranattakal and Puthukulam Grame Niladhari Divisions in the Vavuniya District. There are no large settlements in the above area. However, there are lands under cultivation for which there are 103 claimants either singly or jointly. The population who would be affected is mostly rural, who generally depend on agriculture.

Due to the construction of the proposed reservoir 326 ha land will be inundated, which consists of 65.87 ha paddy land, 14.93 ha upland cultivation land, 16.55 ha of light jungle and 218 ha of forest land. The uplands are cultivated seasonally with other field crops. The forests comprise of dry mixed evergreen forests, riverine forests and shrub forests. There are 3 small tanks in the project area of which the entire command areas plus one tank will be submerged due to the project while portion of the command area of another will be inundated. A Hindu temple and 3 small houses located in the area would be inundated due to the reservoir.

Construction of the proposed reservoir will reduce water to the downstream area, which will cause impacts on aquatic fauna and flora in the tank bed and downstream. The Wildlife Department shows concern on this aspect of the project.

During the past civil unrest period, some of the land which had been under cultivation had been abandoned and subsequently had turned into a light jungle. However, due to its culmination people are returning to their original land and also many are being resettled in new areas which had been under a forest land use hitherto. In order to facilitate sustainable development while conserving the important ecosystems, an integrated strategic environmental assessment has been done for the Northern Province spearheaded by the Central Environment Authority and coordinated and funded by the UNDP. According to a zoning proposed by this study the planned reservoir and the water treatment plant fall within a proposed jungle corridor between Padaviya tank Sanctuary and Vavunikulam Sanctuary. The forest reserves located in close proximity to the proposed reservoir are Melkulam Forest Reserve and Rasenthirakulam Forest Reserve.

Forest Department is very much concerned on trees to be uprooted in the forest land that will be inundated due to the construction of the proposed reservoir since there are valuable trees in that particular forest reserve.

Thus, NWSDB, Forest Department, Wildlife Department, People in the area have conflicting views on the implementation of the proposed 
project to supply water to the urban area of the Vavuniya district. The objective of the paper is to investigate the conflict among these parties to propose an effective solution strategy to solve the conflict. The decision support system, called GMCR II [2], [3], [4], [5], [6], developed for implementing the graph model for conflict resolution, is used to rigorously analyze the conflict.

\subsection{Multiple Participant - Multiple Objective Decision Making in Water Resources}

A conflict over water involves more than one decision maker, participant, or stakeholder. For instance, water conflicts occurring in drainage basins located throughout the world concern many different interest groups, such as national and regional governments, nongovernmental organizations, environmentalists, industries, agriculture, and individual citizens [7]. As water can be used for multiple purposes, often a given interest group is directly associated with a specific use of water such as irrigation, recreation, human consumption, navigation, hydro power generation, etc. Whatever the case, there is almost always disagreement among people and organizations over how water should be utilized in a sustainable fashion that is fair to all of the stakeholders [8].

\subsection{The Graph Model for Conflict Resolution}

The Graph Model for Conflict Resolution (GMCR) is a comprehensive methodology devised to understand conflict decision-making and conflict resolution [9]. The graph model has been designed to be simple and flexible, as well as to have minimal requirements of information.

The original idea of GMCR was introduced by Kilgour et al. [10] while the first complete presentation was furnished by Fang et al. [11]. The GMCR has been applied to a wide range of application areas: from environmental management to labour management; from military and peace-keeping activities to economic issues; from local to international levels [9], [12].

Figure 2 illustrates the general procedure for applying the methodology of GMCR to a realworld conflict. Two main stages, modeling and analysis, are involved in this procedure. In the modeling stage, essential model elements, such as the decision makers (DMs), their options, and the relative preferences are identified based on the understanding of the actual dispute. The objective is to find some stable states that represent a resolution of the conflict. The essential parts of a graph model in option form are the DMs and the options available to each DM. In general, a DM may exercise any combination of the options he or she controls to create a strategy. When every DM has selected a strategy, a state is defined. States are derived from the given options. Then this information is fed into the next stage; analysis.

In the analysis stage, the stability of every state is first calculated from each DM's viewpoint. Subsequently, the overall equilibria, which contain the states that are stable for all DMs, can be obtained. By interpretation and sensitivity analyses, DMs or other interested parties can understand the meaning of resolutions in terms of the real-world disputes. Note that feedback is allowed in the procedure. Feedback means that, at every step of the modeling or analysis stage, one may return to any previous point whenever new information is found. This characteristic makes GMCR more flexible and practical.

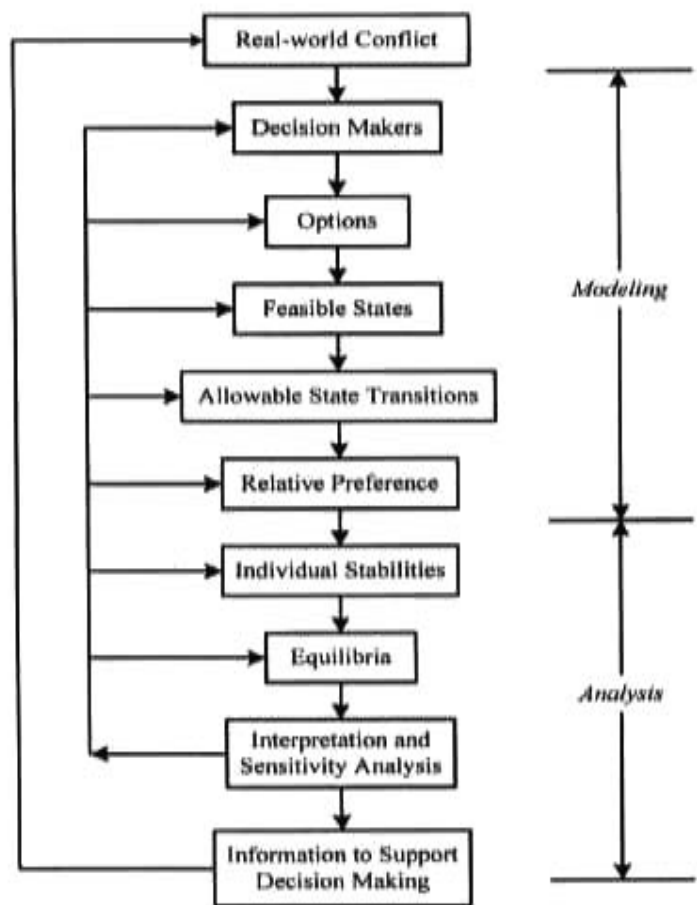

\section{Figure 2 - General procedures for applying} GMCR

The structure of GMCR II, which is the present version of the GMCR, is illustrated in Figure 3. Through the user interface, "Modeling 
Subsystem" build up the graph model with all related information, such as the DMs, their corresponding options, infeasibility information, and last but not least, preferences. Then, the modeling information enters the "Analysis Engine" for further investigation. The important analysis procedures, such as stability analysis, coalition analysis, and status quo analysis, are carried out in this subsystem. Finally, the analysis results or resolutions, for instance, individual stabilities, overall equilibria, and coalition stabilities, are constructed in the "Output Interpretation Subsystem" and delivered to the users through the Graphical User Interface. For a special user who has particular requirements, these requests may be directed additionally from the user interface to the "Analysis Engine".

Within each subsystem, GMCR II has its specific design to complete the functions. For example, preference information is one of the most critical and intractable issues. In GMCR II, this job could be fulfilled by three technologies, option weighting, option prioritizing, and direct ranking. Each technology is employed to deal with a certain situation, and the direct ranking method can be combined with one of other two to fine tune the preferences. Details about GMCR II may be found in Fang et al. (2003a, 2003b).

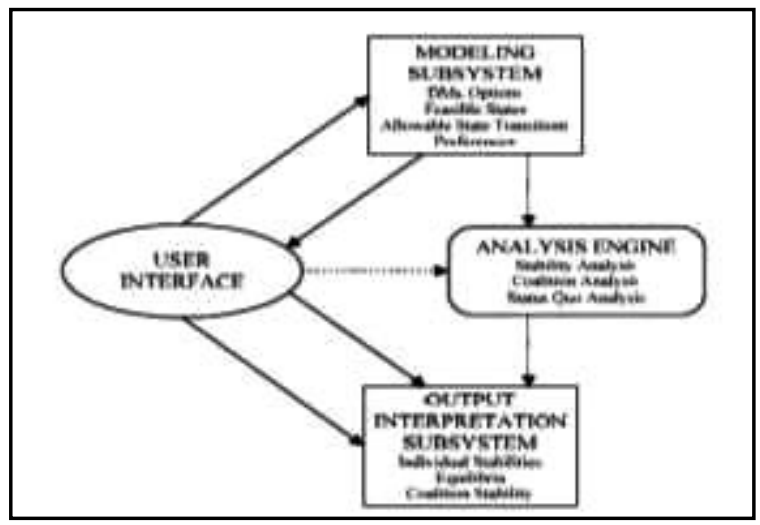

Figure 3 - GMCR II structure

\section{Deveopment of the model}

\subsection{Modeling: Putting the Problem into Perspective}

The paper focus on issues existing in the Per Aru basin due to the proposal for constructing a reservoir to extract water for drinking purpose. The proposed project has created a conflict between three main parties. They are;
- People who would be affected

- National Water Supply \& Drainage Board (NWSDB)

- Government Organizations (Forest Department, Wild Life Department and Central Environmental Authority)

GMCR II is utilized to model the conflict existing in the Per Aru basin by following the steps shown in Figures 2 and 3.

\subsection{Decision Makers and Options}

As the first step in gathering information to understand the conflict and to make it amenable to systematic modeling and analysis, decision makers and their options were identified. The decision makers should have the ability to make decisions that can directly bear upon the eventual resolution of the dispute. Options are specific actions that can actually occur in a conflict. Each decision maker can select which options to implement during the evolution of the conflict.

Table 1 lists the decision makers and their options in the Per Aru basin dispute. As depicted in Figure 3, a conflict model can be updated at any time during the modeling and analysis process to reflect the obtaining of more information about the conflict or a better understanding of the true situation.

Table 1- Decision Makers and their options in the conflict existing in Per Aru basin

\begin{tabular}{|c|c|}
\hline \multicolumn{2}{|c|}{ AP : Affected People } \\
\hline 1 & $\begin{array}{l}\text { Change Location: Change the Project } \\
\text { Location }\end{array}$ \\
\hline 2 & $\begin{array}{l}\text { Reduce paddy inundation: Reduce the } \\
\text { inundation of paddy land under the } \\
\text { reservoir }\end{array}$ \\
\hline \multicolumn{2}{|c|}{ GOV : Government Organizations } \\
\hline 3 & $\begin{array}{l}\text { Sufficient e-flow: Release of sufficient } \\
\text { environmental flow }\end{array}$ \\
\hline 4 & $\begin{array}{l}\text { Reduce total inundation: Reduce the } \\
\text { inundation of forest and paddy land } \\
\text { under the reservoir }\end{array}$ \\
\hline 5 & $\begin{array}{l}\text { Acceptable compensation: Acceptable } \\
\text { compensation to affected people }\end{array}$ \\
\hline \multicolumn{2}{|c|}{$\begin{array}{l}\text { NWSDB : National Water Supply \& Drainage } \\
\text { Board }\end{array}$} \\
\hline 6 & $\begin{array}{l}\text { Reduce e-flow: Reduce environmental } \\
\text { flow }\end{array}$ \\
\hline 7 & $\begin{array}{l}\text { Increase capacity: Increase the } \\
\text { reservoir capacity }\end{array}$ \\
\hline
\end{tabular}




\subsection{Feasible States}

The model in Table 1 contains 7 options, each of which can be selected or not, mathematically there are $2^{7}=128$ possible states. However, not all combinations of options are feasible in practice and of those that are feasible, not all are distinguishable. Subsequent to entering the decision makers and options, infeasible states were identified, which GMCR II will remove from the model, and the groups of states that are effectively identical, which GMCR II will combine into a single state. These steps enable GMCR II to list all states that can actually occur in the model. In the model of the Per Aru basin conflict, there are only 16 feasible states (Figure 6), which is much less than the total number of mathematically possible states.

The model has dialogue boxes for selecting "Mutually Exclusive Options", "At Least One Option", "Option Dependence" and "Direct Specification". In this model two categories of infeasible states are removed: (i) "Mutually Exclusive" options, which remove the states that contain mutually exclusive options, and (ii) "At Least One" option, which is used to specify that, for the set of options, at least one option must be selected.

In the Per Aru basin model, the two options under the control of the "Affected People" are mutually exclusive and, hence, the "Affected People" can only select at most one of their two options, which are numbered as Options 1 and 2 in Figure 4. Thus, if the affected people were to stick with "Change the project location" (Option 1), their other option of "Reduce the inundation of paddy land under the reservoir" (Option 2) could not occur. Likewise, Options 4 and 5 are mutually exclusive for "Government Organizations". If the inundation areas of the paddy and forest lands are reduced (option 4) their other option of "Acceptable compensation to affected people" (option 5) could not occur. However, Option 3 does not have any mutually exclusive options as environmental flow is mandatory for any reservoir project. For the NWSDB, the options 6 and 7 are mutually exclusive. If the NWSDB could increase the reservoir capacity there is no need to reduce the environmental flow and vice versa. The X's that are entered in a given column in Figure 4 designate options those are mutually exclusive.

Figure 5 shows the dialogue box to select the "At Least One Option". The "Affected People" should select at least one of their two options, which are numbered as Options 1 and 2 in Figure 5. Thus, the affected people were to stick with "Change the project location" (Option 1) or their other option of "Reduce the inundation of paddy land under the reservoir" (Option 2).

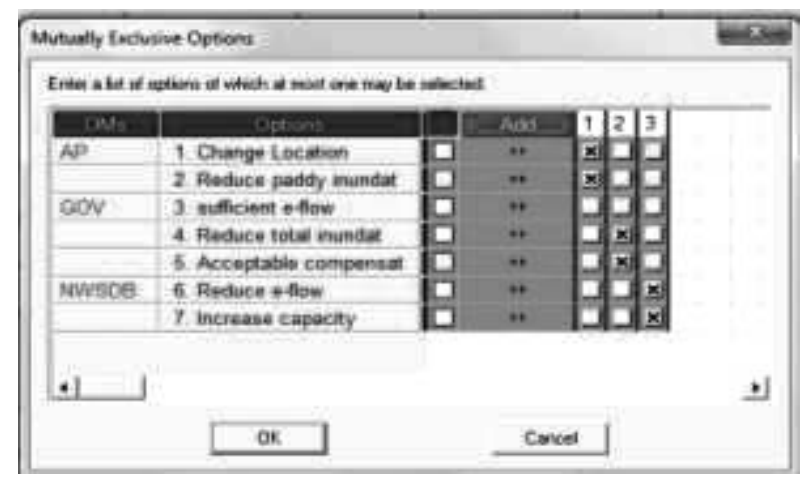

Figure 4- Remove infeasible state using "Mutually Exclusive Options"

Likewise, the government organizations selected "Reduce the inundation of paddy and forest land (Options 4) or "Acceptable compensation to affected people" (Option 5). The NWSDB should select at least one of their options, which are numbered as options 6 and 7 in Figure 5. Thus, the NWSDB selected "Reduce the environmental flow" (Option 6) or "Increase the reservoir capacity" (Option 7).

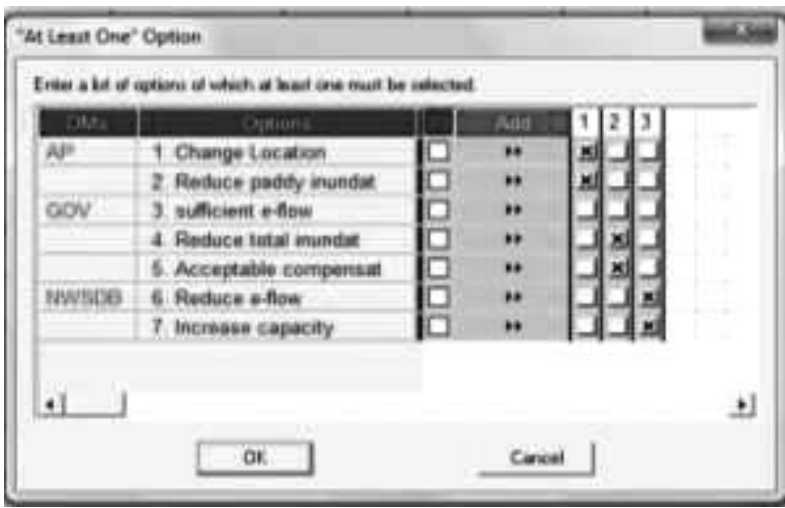

\section{Figure 5- Remove infeasible state using "At} least one option"

After GMCR II removes the infeasible states, the remaining feasible states are listed as columns of $Y^{\prime}$ 's and N's, where " $Y$ " indicates "yes," the option opposite the $\mathrm{Y}$ is selected by the decision maker controlling it, and " $\mathrm{N}$ " means "no," the option is not taken. The 16 feasible states for the Per Aru basin dispute are listed in Figure 6. For convenience, each state is assigned a number. For example, Figure 6 shows that at State 16, the "Affected People" select its second option, but not its first option, to form its strategy NY. The "Government 
Organizations" have taken Option 3 and 5, but not 4, and therefore, have adopted its strategy YNY. Finally, the NWSDB select its second option, but not its first option, so has followed the strategy NY. When strategy selections of all decision makers are combined, State 16, or (NY YNY NY) written horizontally in text, is the result.

\subsection{Allowable State Transition}

At any state of a conflict model, a particular decision maker may be able to unilaterally cause a transition to another state by changing his or her option selection. The GMCR II automatically calculates all possible state transitions, if any, from each state for each decision maker. However, some transitions may be infeasible.

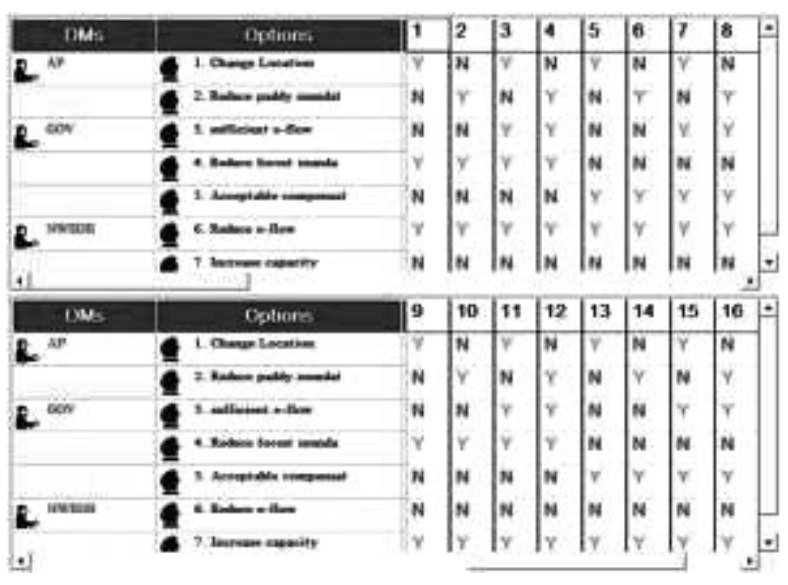

\section{Figure 6 - Feasible States}

This occurs, for instance, when an option is irreversible - after the option is selected, it cannot be undone. In this Per Aru basin conflict model affected people decided to change their option selection "Change the project location" from $\mathrm{Y}$ to $\mathrm{N}$. In the same manner NWSDB decided to change their option selection "Reduce the environmental flow" from $\mathrm{Y}$ to $\mathrm{N}$. Therefore, as illustrated in Figure 7 all the options are reversible other than options 1 and 6 .

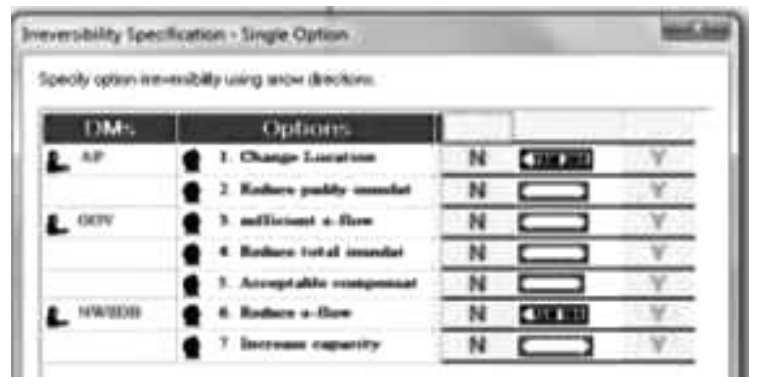

Figure 7 - Allowable state transition in the Per Aru basin conflict

\subsection{Relative Preferences}

Before carrying out a stability analysis, the GMCR II requires that the feasible states be ranked from most to least preferred for each DM, where ties are allowed. The GMCR II possesses two flexible approaches, called "Option Weighting" and "Option Prioritization," for conveniently specifying preference information in terms of options for each DM. An internal algorithm then automatically orders the states for the DM based upon this preference information.

Option Weighting allows users to assign a number or numerical weight to each of the options from the viewpoint of each DM, where a positive or negative number means the DM likes or does not like the option, and the magnitude of the number reflects the degree of preference. Option prioritization provides an intuitive specification based on preference statements listed from most important at the top to least important at the bottom. In addition to these two means to specify the ranking of feasible states for each DM, the GMCR II also allows users to fine-tune the preference ranking by directly reordering states, joining two or more states into an equally preferred group, and splitting an equally preferred group apart. Option Prioritization along with "Direct Ranking" is employed to come up with the preference ranking for the DMs in the Per Aru basin conflict. Table 2 lists the preference statements using option numbers in order of priority for each DM.

Table 2 - Lexicographic Preference Statements for the DMs expressed in terms of options

\begin{tabular}{lll}
\hline AP & GOV & NWSDB \\
\hline 2 & $3 \&-6$ & -1 \\
1 IF 7 & $4 \& 2 \&-7$ & $-2 \&-4$ \\
5 & 5 & 5 \\
$3 \&-6$ & -1 & $6 \&-3$ \\
4 & & 7 IF 3 \\
\hline
\end{tabular}

Consider the preference statements of the Affected People (AP) given in the left-hand column in Table 2. The Option 2 located at the top of the first column means that AP most prefers to reduce the inundation area of the reservoir. As indicated by " 1 if 7 " written below the Option 2, the $\mathrm{AP}^{\prime} \mathrm{s}$ next preference is to change the reservoir location if the reservoir capacity is to be increased. In the order of 
decreasing preference, AP would like to accept the compensation package (Option 5). Next, AP would like sufficient e-flow (Option 3) and AP do not want NWSDB to reduce the e-flow (Option 6). Finally, AP like to reduce the inundation of forest land.

The middle column of Table 2 lists Government Organization (GOV)'s preference statements. As can be seen, it most prefers to release sufficient e-flow and it prefers NWSDB not to reduce the e-flow (Options $3 \& 6$ ). The second level preference is for it to reduce the inundation area of the paddy land, reduce the inundation of forest land and NWSDB not to increase the reservoir capacity (Option $2 \& 4$ \& 7). This is followed by acceptable compensation package to affected people (Option 5). At last it prefers NWSDB not to change the location of the reservoir (Option 1).

As indicated in the third column from the left in Table 2, NWSDB most prefers not to change the project location (Option 1). Next, NWSDB prefers not to reduce the inundation of paddy land and forest land (Option $-2 \&-4)$. Then it prefers to give the acceptable compensation package to affected people (Option 5). Subsequently, NWSDB prefers to reduce the eflow (Option 6) and not to release sufficient eflow (Option 3). Finally, NWSDB prefers to increase the reservoir capacity if the sufficient environmental flow is mandatory (Option 7 IF 3).

A remarkable advantage of the option prioritization approach to preference elicitation is that it closely reflects the way in which a person thinks about preferences in a given dispute. What clients find to be stunning about the graph model methodology is that relative preference information can furnish detailed and accurate analytical results, such as the potential resolutions to the conflict under study.

When employing the GMCR II, a user only needs to enter known preference statements expressed in terms of options for a given decision maker. In fact, these preference statements adhere to all of the rules of first order logic. Assuming transitivity of preferences, the GMCR II possesses an algorithm for taking the prioritized preference statements for each decision maker to produce a ranking of states for each decision maker in which ties are permitted. Often, a given decision maker's most and least preferred preference statements are initially known.
After the GMCR II ranks the states based on a limited number of preference statements, there may be blocks of equally preferred states contained within the ordering of states. As more preference information becomes available, these equally preferred blocks will become less prevalent and will fully disappear when there are sufficient preference statements to produce complete ranking of states from most to least preferred with no ties. However, even when there are blocks of equally preferred states for one or more decision makers, the GMCR II can still carry out stability analyses. In practice, this means that one can commence with a "quick and dirty" analysis and subsequently refine preference statements as more information becomes available. Finally, it should be stressed that a user only has to supply preference statements in terms of what is usually not a large number of options. The user does not have to order the states, which in some cases can be relatively large,the GMCR II expeditiously determines the ordering using the lexicographic preference statements supplied by the user. In fact, an appealing feature of the graph model methodology is that the user only needs to supply relatively small amounts of information to calibrate a conflict model upon which highly accurate analytical results can be ascertained.

Table 3 displays the preference ranking of states from most preferred at the top to least preferred at the bottom for each of the three decision makers.

Table 3- Ranking of States for Decision Makers

\begin{tabular}{rrr}
\hline \multicolumn{1}{c}{ AP } & GOV & NWSDB \\
\hline 8 & 16 & 6 \\
6 & 15 & 14 \\
2 & 12 & 16 \\
4 & 11 & 8 \\
16 & 4 & 2 \\
14 & 2 & 10 \\
12 & 14 & 12 \\
10 & 8 & 4 \\
15 & 6 & 5 \\
7 & 7 & 15 \\
13 & 5 & 13 \\
5 & 13 & 7 \\
11 & 10 & 1 \\
3 & 9 & 11 \\
9 & 3 & 9 \\
1 & 1 & 3 \\
\hline
\end{tabular}


Notice that $\mathrm{AP}^{\prime} \mathrm{s}$ most preferred State is 8 , as indicated by the placement of 8 at the top of the left-hand column in Table 3 , and least preferred State 1 is, shown at the bottom. Further, the "power" held by a participant in a dispute is reflected by the options available to the decision maker and the decision maker's preferences over states.

\section{Analysis and results}

\subsection{Deciding What to Do}

After a model has been established, the analysis phase of the GMCR II is invoked, as is indicated in the lower portion of Figure 2. A GMCR II analysis includes a determination of the stability of every state, for every decision maker, under all solution concepts listed in Table 4 . These stability definitions describe the patternsof interaction that a decision maker may expect. If it is not advantageous for a given decision maker to depart unilaterally from a particular state according to a given solution concept, then the state is deemed to be stable for that decision maker under that solution concept. If a state is stable according to a given solution concept, for all of the decision makers, it constitutes an equilibrium under that solution concept. It is, therefore, a compromise resolution, since no decision maker has an incentive to unilaterally move away from it. Fang et al. (1993) present mathematical definitions and comparisons as well as original references for the solution concepts given in Table 4.

Subsequent to executing a stability analysis, the GMCR II can display stability results separately for each decision maker as well as the equilibria. Table 5 lists the individually stable states for the three decision makers and the equilibrium states for the Per Aru basin conflict.

Table 4- Individual Stability States and Equilibrium States

\begin{tabular}{rrrr}
\hline \multicolumn{3}{c}{ Individual Stability } & Equilibria \\
\cline { 1 - 3 } AP & GOV & NWSDB & \\
\hline 2 & 2 & 1 & 2 \\
4 & 4 & 2 & 16 \\
6 & 5 & 5 & \\
8 & 7 & 6 & \\
10 & 15 & 7 & \\
12 & 16 & 8 & \\
14 & & 9 & \\
16 & & 10 & \\
& & 11 & \\
& & 12 & \\
& & 13 & \\
& & 14 & \\
& & 16 & \\
& & & \\
\end{tabular}

Figure 8 is the Equilibrium list for the Per Aru basin conflict, which illustrates the two possible resolutions' strong stabilities.

Table 5- Solution Concepts and Human Behaviour

\begin{tabular}{ll}
\hline Solution concept & Stability description \\
\hline $\begin{array}{l}\text { Nash stability } \\
\text { General metarationality }\end{array}$ & $\begin{array}{l}\text { DM cannot unilaterally move to a more preferred state } \\
\text { All DM's unilateral improvements are sanctioned by subsequent } \\
\text { unilateral move by others }\end{array}$ \\
$\begin{array}{l}\text { Symmetric metarationality } \\
\text { (SMR) }\end{array}$ & $\begin{array}{l}\text { All DM's unilateral improvements are still sanctioned even after } \\
\text { possible responses by the original DM }\end{array}$ \\
Sequential stability (SEQ) & $\begin{array}{l}\text { All DM's unilateral improvements are sanctioned by subsequent } \\
\text { unilateral improvements by others }\end{array}$ \\
Limited-move stability $\mathrm{L}_{h}$ & $\begin{array}{l}\text { All DM's are assumed to act optimally and maximum number of } \\
\text { state transitions }(h) \text { is specified }\end{array}$ \\
Nonmyopic (NM) & $\begin{array}{l}\text { Limiting case of limited move stability as the maximum number of } \\
\text { state transitions increase to infinity }\end{array}$
\end{tabular}


R, GMR, SMR, SEQ, NM, and L (2) in the lower rows correspondinglyrepresent Nash Stability, General Metarationality, Symmetric Metarationality, Sequential Stability with a horizon of two, Non-Myopic Stability and Limited Move Stability. The tick in the column of each state indicates that the state is in equilibrium under the corresponding solution concept in that row.Undoubtedly, States 2 and 16 are equilibria under all listed solution concepts.

\begin{tabular}{|c|c|c|c|c|c|}
\hline DMs & Options & & & 2 & 16 \\
\hline \multirow[t]{2}{*}{ E. AP } & 1. Change Location & - & $\div$ & $\mathbf{N}$ & $\mathbf{N}$ \\
\hline & 2. Reduce paddy innndat & - & $\div$ & $\mathbf{Y}$ & $\mathbf{Y}$ \\
\hline \multirow{3}{*}{ cov } & 3. sufficient e-flow & - & 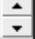 & $\mathbf{N}$ & $\mathbf{Y}$ \\
\hline & 4. Reduce forest innnda & - & $\div$ & $\mathbf{Y}$ & $\mathbf{N}$ \\
\hline & 5. Acceptable compensat & - & $\hat{\imath}$ & $\mathbf{N}$ & $\mathbf{Y}$ \\
\hline \multirow[t]{9}{*}{ A. NWSDB } & 6. Redace e-flow & - & $\vdots$ & $\mathbf{Y}$ & $\mathbf{N}$ \\
\hline & 7. Increase capacity & - & $\stackrel{5}{*}$ & $\mathbf{N}$ & $\mathrm{Y}$ \\
\hline & $\mathbf{R}$ & & & $\square$ & $\square$ \\
\hline & GMR & & & $\nabla$ & $\square$ \\
\hline & SMR & & & $\nabla$ & $\nabla$ \\
\hline & SEQ & & & $\nabla$ & $\nabla$ \\
\hline & NM & & & $\nabla$ & $\nabla$ \\
\hline & L[2] & & & $\nabla$ & $\nabla$ \\
\hline & Add Custom Type & & & & \\
\hline
\end{tabular}

\section{Figure 8 - Equilibrium list for the Per Aru} basin conflict

\subsection{State transitions from Status Quo to Final Outcome}

Table 6 shows the sequence of state transitions from the status quo to the final equilibrium state 16, where arrows indicate the location and direction of option changes during the evolution of the conflict. At the status quo, "Affected People" enforced to change the reservoir location or forced to reduce the inundation of paddy land. However, attempts by the NWSDB to reduce the inundation of paddy land by extend the bund, would encourage the Affected People to accept the project location without changing as shown in the joint transition from Status quo to State 6. Hence, by exhibiting a spirit of cooperation, Affected People, Government Organizations and NWSDB can jointly move the conflict to State 14, which is more preferred than State6 by all decision makers. Finally, State 16, in which NWSDB decided to release sufficient environmental flow, could be an acceptable solution for all the parties.
Table 6 - State transitions from Status Quo to Final Outcome

\begin{tabular}{|c|c|c|c|c|}
\hline \multirow[b]{2}{*}{ Transition } & \multicolumn{4}{|c|}{ State Number } \\
\hline & $\begin{array}{c}\text { Status } \\
\text { Quo }\end{array}$ & 6 & 14 & 16 \\
\hline \multicolumn{5}{|l|}{ Affected People } \\
\hline Change location & Y & $\mathrm{N}$ & $\mathrm{N}$ & $\mathrm{N}$ \\
\hline $\begin{array}{l}\text { Reduce paddy } \\
\text { inundation }\end{array}$ & $\mathrm{N}$ & $\mathrm{Y}$ & Y & $\mathrm{Y}$ \\
\hline \multicolumn{5}{|c|}{ Government Organizations } \\
\hline Sufficient e-flow & $\mathrm{N}$ & $\mathrm{N}$ & $\mathrm{N}$ & Y \\
\hline $\begin{array}{l}\text { Reduce total } \\
\text { inundation (Forest) }\end{array}$ & $\mathrm{N}$ & $\mathrm{N}$ & $\mathrm{N}$ & $\mathrm{N}$ \\
\hline $\begin{array}{l}\text { Acceptable } \\
\text { compensation }\end{array}$ & Y & Y & Y & $\mathrm{Y}$ \\
\hline \multicolumn{5}{|l|}{ NWSDB } \\
\hline Reduce e-flow & Y & $\mathrm{Y}$ & $\mathrm{N}$ & $\mathrm{N}$ \\
\hline $\begin{array}{l}\text { Increase reservoir } \\
\text { capacity }\end{array}$ & $\mathrm{N}$ & $\mathrm{N}$ & Y & $\mathrm{Y}$ \\
\hline
\end{tabular}

\section{Conclusions}

As demonstrated by the Per Aru basin conflict study, the Graph Model for Conflict Resolution methodology, in conjunction with the decision support system GMCR II, furnishes a valuable decision technology for systematically and rigorously investigating real-world conflict. Moreover, the analytical results provide strategic insights into how the conflict evolved from a status quo situation to its final resolution.

In the Per Aru basin conflict the affected people most preferred to change the project location. As per the preference order Government Organizations, most preferred to release sufficient environmental flow. However, as the NWSDB accepted to reduce the inundation of paddy land and agreed to release sufficient environmental flow, the affected people and Government Organizations agreed to construct the reservoir at the original location. 


\section{$5 \quad$ References}

1. Environmental Impact Assessment (EIA), 2012. Surface water extraction from a reservoir across Per Aru.

2. Fang, L., Hipel, K.W., Kilgour, M.D., and Peng, X.,"A Decision Support System for Interactive Decision Making, Part 1: Model Formulation", IEEE Transactions on Systems, Man, and Cybernetics, Part C, Vol. SMC-33, No. 1, 2003.

3. Fang, L., Hipel, K.W., Kilgour, D.M., and Peng, X., "A Decision Support System for Interactive Decision Making, Part 2: Analysis and Output Interpretation", IEEE Transactions on Systems, Man, and Cybernetics, Part C, Vol. SMC-33, No. 1, 2003.

4. Hipel, K.W., Kilgour, D.M., Fang, L., and Peng, X., "The decision support system GMCR II in environmental conflict management",Applied Mathematics and Computation 83, No.2 and 3: 1997, pp.117152.

5. Hipel, K.W., Kilgour, D.M., Fang, L., and Peng, X., "Strategic Decision Support for the Services Industry." IEEE Transactions on Engineering Management 48, No.3: 2001, pp.358-369.
6. Kilgour, D.M., Hipel, K.W., Fang, L., and Peng, X.,. "Coalition Analysis in Group Decision Support." Group Decision and Negotiation 10, No.2: 2001, pp.159-175.

7. Wolf, A., ed.,Conflict prevention and resolution in water systems, Elgar, Cheltenham, U.K.2002.

8. Gleick, P. H., "Water and conflict: Fresh water resources and international security", Int. Secur., 18(1),1993.

9. Kilgour, D.M. and Hipel, K.W. The graph model for conflict resolution: past, present, and future," Group Decision and Negotiation, 14(6),2005.

10. Kilgour, D.M., Hipel, K.W., and Fang, L. "The graph model for conflicts," Automatica, 23(1),1987.

11. Fang, L., Hipel, K.W., and Kilgour, D.M. Interactive Decision Making: The Graph Model for Conflict Resolution. Wiley, New York,1993.

12. Nandalal, K.D.W. and Hipel,K.W. "Strategic Decision Support for Resolving Conflict over Water Sharing along the Syr Darya River in the Aral Sea Basin", Journal of Water Resources Planning and Management, ASCE, Vol.133, Issue 4, 2007, pp.289-299. 